\title{
Tác động của đầu tư công đến thu hút đầu tư tư nhân và tăng trưởng kinh tế tại Việt Nam
}

\section{The effect of public investment on private investment and economic growth in Vietnam}

\author{
Nguyễn Thị Cành ${ }^{1 *}$, Nguyễn Thanh Liêm ${ }^{1}$, Nguyễn Thị Thùy Liên ${ }^{1}$ \\ ${ }^{1}$ Trường Đại học Kinh tế - Luật, Đại học Quốc gia Thành Phố Hồ Chí Minh, Việt Nam \\ "Tác giả liên hệ, Email: canhnt@uel.edu.vn
}

THÔNG TIN

DOI: $10.46223 / \mathrm{HCMCOUJS.}$

econ.vi.13.2.511.2018

Ngày nhận: 11/01/2018

Ngày nhận lại: 02/02/2018

Duyệt đăng: 26/02/2018

\section{Tù khóa:}

đầu tư công, đầu tư khu vực nhà nước, tăng trưởng kinh tế, tổng đầu tư tư nhân

\section{TÓM TẮT}

Nghiên cứu áp dụng phương pháp đồng liên kết (Fully Modified OLS và Dynamic Panel OLS) để đánh giá tác động dài hạn của đầu tư công đối với đầu tư tư nhân và tăng trưởng kinh tế bằng cách sử dụng dữ liệu từ 22 ngành kinh tế cấp 1 trong khoảng thời gian 27 năm (1990-2016). Nghiên cứu đã đưa ra bằng chứng nhất quán về hiệu quả tích cực của đầu tư công và đầu tư tư nhân đối với tăng GDP ngành ở Việt Nam. Kết quả cho thấy đầu tư công không chỉ giúp thúc đẩy đầu tư của khu vực tư nhân mà còn làm tăng GDP trong dài hạn. Bằng chứng này rất quan trọng trong việc quyết định có nên duy trì đầu tư từ khu vực chính phủ hay không. Tuy nhiên, có một số bằng chứng cho thấy đầu tư từ doanh nghiệp nhà nước không hiệu quả. Bởi vì khi kết hợp đầu tư của doanh nghiệp nhà nước với đầu tư công thành đầu tư của khu vực nhà nước cho thấy ảnh hưởng của đầu tư khu vực nhà nước có tác động làm giảm tác động tích cực của đầu tư nhà nước đối với GDP so với tác động riêng biệt của đầu tư công. Kết quả này gợi ý chính sách cần cơ cấu lại khu vực công nói chung và khu vực doanh nghiệp nhà nước nói riêng tại Việt Nam.

\section{ABSTRACT}

The study used a co-integration method (Fully Modified OLS and Dynamic Panel OLS) to assess the long-run impact of public investment on private investment and economic growth, using data from 22 economic industries over a 27 -year period (1990-2016). We have obtained strongly consistent evidence of the positive effect of private and public investment on industrial GDP in Vietnam. We find that public investment not only helps spur private investment, but also boosts GDP in the long run. This evidence is important in deciding whether to maintain the public investment, state sector investment, economic growth, total private investment 
investment from the public sector. Nonetheless, there is some evidence suggesting that the investment from state-owned enterprise is not as efficient as the public investment in infrastructure. However, the investment from state-owned enterprise combined with public investment tends to decline effects on GDP, thus calling for the further restructuring of the state-owned enterprises in Vietnam.

\section{Giới thiệu}

Việt Nam qua 30 năm thực hiện chính sách đổi mới kinh tế và đã thu được những thành quả đáng khích lệ với tốc độ tăng trưởng kinh tế cao so với nhiều nước trong khu vực và ổn định trong nhiều năm. Nền kinh tế Việt Nam đang hội nhập sâu vào nền kinh tế thế giới, chính sách tài khóa được cải thiện (thu, chi ngân sách được cân đối phù hợp với qui mô nền kinh tế, tỷ lệ bội chi trong giới hạn cho phép) đã tạo được niềm tin cho các nhà đầu tư và các tổ chức tài trợ quốc tế. Tuy nhiên, từ đầu năm 2007 Việt Nam đã trở thành thành viên chính thức của tổ chức thương mại thế giới (WTO), đầu năm 2016 cộng đồng kinh tế các nước ASEAN-AEC bắt đầu hoạt động. Việt Nam đã và đang thực hiện lộ trình cắt giảm thuế quan theo các cam kết hội nhập. Cắt giảm thuế quan có nghĩa là một phần nguồn thu cho ngân sách theo các dòng thuế quy định sẽ bị giảm, cùng với giá dầu giảm nguồn thu cũng giảm mạnh, trong khi Việt Nam vẫn cần duy trì các khoản chi cho hoạt động của chính phủ, chi cho các sự nghiệp kinh tế, xã hội và chi đầu tư phát triển cơ sở hạ tầng còn quá yếu kém. Trong bối cảnh có sức ép cao về ngân sách yêu cầu đặt ra phải tiết kiệm chi tiêu của chính phủ. Tuy nhiên, muốn có tăng trưởng phát triển kinh tế, nâng cao sức cạnh tranh của nền kinh tế để thu hút các nguồn đầu tư tư nhân, đầu tư nước ngoài (FDI), cần phải cải thiện môi trường đầu tư, môi trường kinh doanh. Muốn cải thiện môi trường đầu tư, môi trường kinh doanh, vai trò của nhà nước phải cung cấp dịch vụ hàng hóa công thông qua đầu tư vào cơ sở hạ tầng kỹ thuật (đường sá, cầu cống, cảng..., hạ tầng cho các khu công nghiệp, thương mại) và cơ sở hạ tầng xã hội (trường học, bệnh viện...).

Như vậy yêu cầu đặt ra vẫn cần phải tăng cường đầu tư công từ nhà nước, và đầu tư công phải đảm bảo tính hiệu quả thông qua thu hút đầu tư tư nhân và tăng trưởng kinh tế. Hiện các kết quả nghiên cứu về đầu tư công trên thế giới có hai xu hướng đối lập nhau. Xu hướng thứ nhất, nhiều nghiên cứu ở các nước đang phát triển đều có bằng chứng cho rằng đầu tư công có tác động đến đầu tư tư nhân và tăng trưởng kinh tế. Xu hướng thứ hai, có kết quả ngược lại với xu hướng thứ nhất, thể hiện qua kết quả một vài nghiên cứu ở các nước phát triển thì lại cho rằng đầu tư công lấn át đầu tư tư nhân và không hoặc ít tác động hoặc thậm chí tác động nghịch đến tăng trưởng kinh tế. Trong giới hạn phần nghiên cứu thực nghiệm này, chúng tôi muốn xem xét đầu tư công ở Việt Nam có tạo ra hiệu ứng tích cực hay không, tức đầu tư công có tác động đến thu hút đầu tư tư nhân và tăng trưởng kinh tế hay không.

\section{Cơ sở lý thuyết và các nghiên cứu trước}

Lý thuyết giải thích mối quan hệ giữa các nguồn đầu vào và sự tăng trưởng trong sản phẩm quốc dân được gọi là hàm sản xuất. Ở giác độ vi mô hàm sản xuất miêu tả mối tương quan giữa tổng số đầu vào cho trước và tổng đầu ra có thể sản xuất được. Trên giác độ quốc 
gia, hay nền kinh tế rộng lớn, các hàm sản xuất miêu tả mối quan hệ giữa số lượng lao động, vốn tư bản của một quốc gia với mức thu nhập quốc dân của quốc gia đó. Các mối quan hệ rộng lớn này được gọi là các hàm sản xuất tổng hợp. Hàm Sản xuất Cobb - Douglas nghiên cứu ảnh hưởng của các yếu tố về lao động $(\mathrm{L})$ và đầu tư $(\mathrm{K})$ đối với tổng sản phẩm ngành công nghiệp chế tạo $(\mathrm{Y})$. Solow (1956) đã cố gắng giải thích nguồn gốc của sự tăng trưởng bằng một dạng khác của hàm sản xuất cho phép phân tích đánh giá các nguyên nhân hay các nguồn gốc khác nhau của sự tăng trưởng gọi là mô hình Solow. Mô hình Solow tập trung vào 4 biến số: Sản lượng đầu ra $(\mathrm{Y})$, vốn $(\mathrm{K})$, lao động $(\mathrm{L})$ và "kiến thức" hay "hiệu quả lao động" $(\mathrm{A})$. Các giả định chủ yếu của mô hình Solow liên quan đến các đặc tính của hàm sản xuất và sự tiến hóa của 3 yếu tố đầu vào biến thành sản phẩm (vốn, lao động và kiến thức) qua thời gian.

Đầu tư công tác động sâu rộng tới tăng trưởng kinh tế được thể hiện qua hai mặt là tổng cung và tổng cầu. Đầu tư công tác động trực tiếp đến tổng cầu với tư cách chi tiêu chính phủ và tổng cung với tư cách hàm sản xuất (yếu tố vốn). Đầu tư công tác động gián tiếp và lan tỏa đến tổng cầu qua kênh kích thích kênh đầu tư tư nhân và tổng cung qua việc thu hút vốn đầu tư tư nhân.

Như đã nêu, cho đến nay các kết quả nghiên cứu về đầu tư công tác động đến đầu tư tư nhân và tăng trưởng kinh tế trên thế giới vẫn có hai xu hướng đối lập nhau. Xu hướng thứ nhất, nhiều nghiên cứu ở các nước đang phát triển đều có bằng chứng cho rằng đầu tư công có tác động đến đầu tư tư nhân và tăng trưởng kinh tế (nghiên cứu của Bukhari, Ali, \& Saddaqat, 2007; Haque, 2013; Reungsri, 2010; Zainah, 2009; ...). Xu hướng thứ hai, có kết quả ngược lại với xu hướng thứ nhất, thể hiện qua kết quả nghiên cứu ở một số nước đang phát triển và phần lớn các nước phát triển thì lại cho rằng đầu tư công lấn át đầu tư tư nhân và không hoặc ít hoặc tác động nghịch đến tăng trưởng kinh tế (Phetsavong \& Ichihashi 2012; Vedder \& Gallaway, 1998).

Tuy nhiên, một số nghiên cứu trong các nước phát triển cũng thừa nhận rằng, trong ngắn hạn đầu tư công không có tác động đến tăng trưởng kinh tế, nhưng trong dài hạn là có tác động (nghiên cứu của Dreger \& Reimers, 2016). Thực tế cũng đã có nhiều nghiên cứu về tác động của đầu tư công đến tăng trưởng kinh tế ở các nước phát triển và hầu hết đều cho kết luận rằng trong dài hạn thì đầu tư công có tác dụng thúc đẩy đầu tư tư nhân và qua đó có ảnh hưởng tích cực đến tăng trưởng kinh tế hơn là tác dụng lấn át. Auschauer (1989), trong nghiên cứu tác động của đầu tư công tại Mỹ đã đưa ra kết luận rằng đầu tư công làm gia tăng tỷ suất sinh lợi đầu tư và nhờ đó tạo ra được một mức đầu tư cao hơn. Ông cũng chứng minh được rằng trong dài hạn thì ảnh hưởng thúc đẩy của đầu tư công đối với đầu tư tư nhân sẽ lớn hơn nhiều so với ảnh hưởng lấn át và do vậy có ảnh hưởng tích cực đến tăng trưởng kinh tế.

Tại Việt Nam các nghiên cứu về tác động của đầu tư công khá nhiều nhưng chủ yếu ở dạng định tính hoặc lý thuyết và chưa có nhiều nghiên cứu thực nghiệm. Gần đây có một số nghiên cứu thực nghiệm về tác động đầu tư công với tăng trưởng kinh tế. Với mục tiêu kiểm định giả thuyết liệu đầu tư công lấn át hay thúc đẩy đầu tư tư nhân ở Việt Nam hay không, To (2011) sử dụng mô hình vector hiệu chỉnh sai số VECM để ước lượng các hàm phản ứng với các biến đầu tư khu vực nhà nước, đầu tư tư nhân và GDP trong giai đoạn 1986 - 2010. Kết luận của nghiên cứu là cả đầu tư tư nhân và đầu tư công đều có tác động tích cực đến sản lượng 
và có ý nghĩa thống kê, tuy nhiên tác động của đầu tư tư nhân là cao hơn so với đầu tư công. Nghiên cứu của Tran và Le (2014) đã sử dụng mô hình tự hồi quy phân phối trễ (ARDL) để kiểm tra hiệu ứng của đầu tư công đến tăng trưởng kinh tế Việt Nam giai đoạn 1988 - 2012. Kết quả nghiên cứu cho thấy tác động của đầu tư công đối với tăng trưởng kinh tế trong ngắn hạn không có ý nghĩa thống kê, nhưng có tác động thúc đẩy tăng trưởng trong dài hạn.

Tuy nhiên, các nghiên cứu tại Việt Nam sử dụng số liệu đầu tư của khu vực nhà nước bao gồm cả đầu tư công và đầu tư của doanh nghiệp nhà nước (DNNN) cho hoạt động sản xuất kinh doanh để nói tác động của đầu tư công đến tăng trưởng kinh tế tại Việt Nam là không chính xác. Theo luật đầu tư công năm 2014 của Việt Nam (có hiệu lực từ đầu năm 2015), thì đầu tư công bao gồm các lĩnh vực: (i) Đầu tư các chương trình, dự án kết cấu hạ tầng kinh tế xã hội; (ii) Đầu tư phục vụ hoạt động của các cơ quan nhà nước và đơn vị sự nghiệp, tổ chức chính trị, tổ chức chính trị - xã hội ở trong nước và ở nước ngoài; Đầu tư và hỗ trợ hoạt động cung cấp sản phẩm dịch vụ công ích; Theo định nghĩa này thì trong đầu tư công không có đầu tư cho sản xuất kinh doanh của DNNN. Vì vậy, nghiên cứu của chúng tôi với sự hỗ trợ của Vụ Quản lý vốn, Tổng cục Thống kê sẽ tách đầu tư nhà nước ra làm hai loại là đầu tư công theo định nghĩa trên và đầu tư của DNNN cho hoạt động sản xuất kinh doanh, qua đó để đánh giá đúng vai trò của đầu tư công.

Dưới đây sẽ phân tích thực trạng về đầu tư công, đầu tư của DNNN với đầu tư tư nhân và tăng trưởng kinh tế tại Việt Nam cho giai đoạn 1990-2016, trước khi thực hiện nghiên cứu định lượng về tác động của đầu tư công.

\section{Mô tả quan hệ giữa đầu tư công với đầu tư tư nhân và tăng trưởng kinh tế tại Việt Nam}

Tác động của đầu tư công đến đầu tư tư nhân, đầu tư nước ngoài, tổng đầu tư xã hội, đầu tư vào sản xuất kinh doanh và tăng trưởng kinh tế được mô tả qua Hình $1,2,3$ và 4 .

Số liệu thống kê cho thấy tổng vốn đầu tư toàn xã hội trên GDP tăng đều qua các giai đoạn, từ 27,2\% GDP (1990-1995) lên 39,3\% GDP (2006-2010), giảm xuống 31,9\% GDP (2011-2016). Tốc độ tăng tổng đầu tư theo giá cố định năm 2010 qua các giai đoạn cao hơn nhiều so với tốc độ tăng trưởng kinh tế (Hình 1). Điều này cũng cho thấy, tốc độ tăng trưởng kinh tế dựa nhiều vào nhân tố vốn đầu tư. Tốc độ tăng vốn cao hơn tốc độ tăng GDP nhưng cùng xu hướng chậm dần theo thời gian. Cụ thể tăng bình quân vốn là $20,1 \%$ /năm, tăng GDP bình quân 8,2\%/năm giai đoạn (1990-1995); vốn tăng 17,4\%/năm và GDP tăng 6,4\%/năm giai đoạn (1996-2000); vốn tăng 12,3\%/năm và GDP tăng 7,4\%/năm giai đoạn (2001-2005); vốn tăng $13,2 \% /$ năm và GDP tăng $6,2 \%$ /năm giai đoạn (2006-2010); vốn tăng $8,3 \% /$ năm và GDP tăng tăng 5,9\%/năm giai đoạn (2011-2016). 


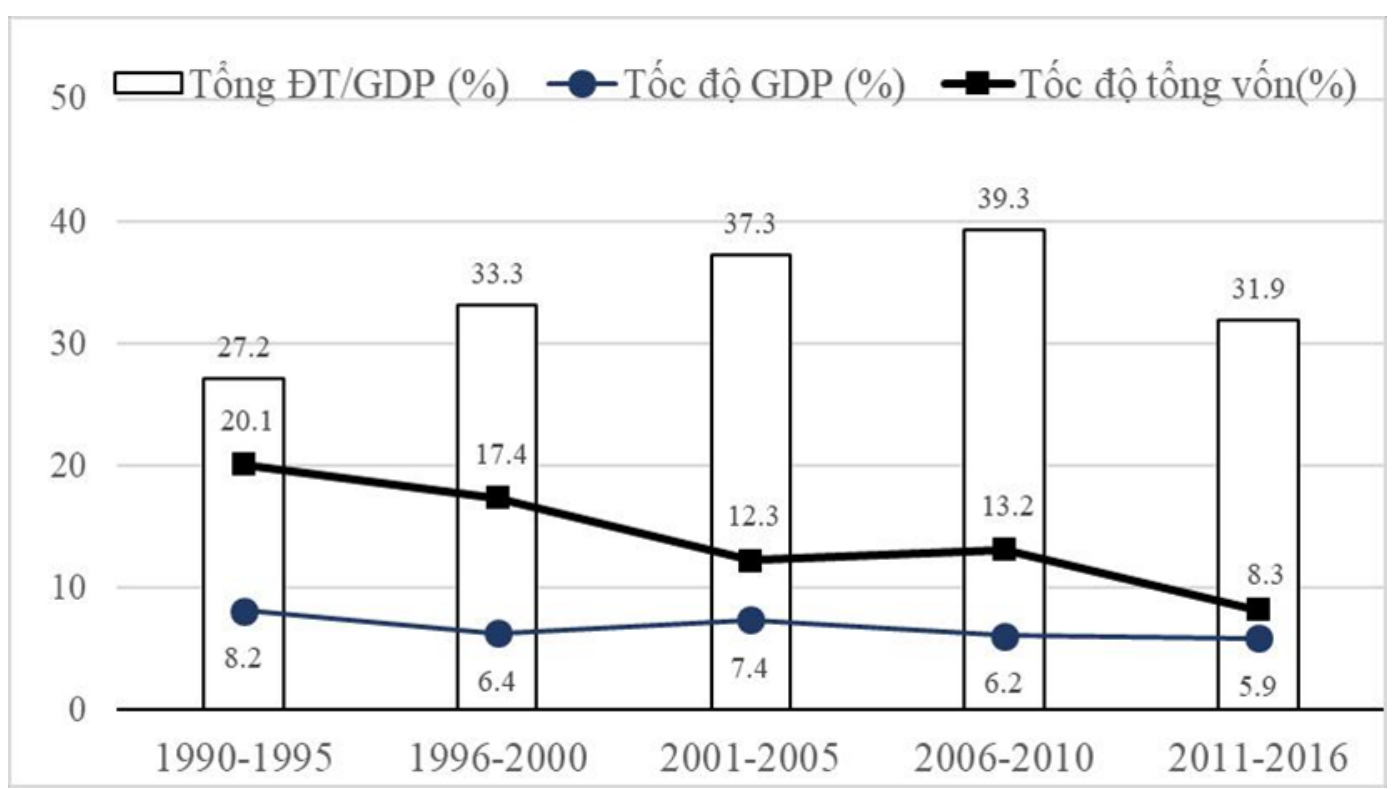

Hình 1. Tổng đầu tư và tăng trưởng kinh tế Việt Nam qua các giai đoạn

Nguồn: Tính toán của tác giả từ nguồn Tổng cục Thống kê

Đầu tư công và đầu tư doanh nghiệp nhà nước có tỷ trọng thu hẹp dần trong suốt giai đoạn 1990-2009, và từ năm 2010 đến nay; Cơ cấu vốn từ khu vực nhà nước dao động xung quanh mức $36 \%$ so với tổng vốn đầu tư toàn xã hội (năm 2016), trong đó vốn cho đầu tư công chiếm trên $20 \%$ và vốn đầu tư cho hoạt động kinh doanh của các doanh nghiệp nhà nước là trên $16 \%$. Riêng đầu tư FDI có nhiều biến động trong cơ cấu vốn, cụ thể là cơ cấu vốn FDI tăng trong các giai đoạn 1990-1994, 2005-2008, nhưng thu hẹp tỷ trọng trong các giai đoạn 19952004, 2009-2012, từ năm 2013 đến nay tỷ trọng vốn FDI có tăng nhẹ nhờ sự phục hồi của nền kinh tế thế giới. Khi vốn đầu tư của khu vực nhà nước được tách thành 2 gồm vốn đầu tư công (đầu tư cho các dự án thuộc cơ sở hạ tầng và đầu tư cho hoạt động sản xuất kinh doanh của doanh nghiệp nhà nước, thì tổng nguồn vốn được tách thành 4 loại vốn theo hình thức sở hữu theo biểu đồ - Hình 2.

Theo Hình 2, cơ cấu vốn đầu tư công - đầu tư phát triển cơ sở hạ tầng có xu hướng không tăng hoặc giảm trong điều kiện cơ sở hạ tầng của Việt Nam còn kém phát triển có thể làm hạn chế tác động tích cực của đầu tư công đến thu hút đầu tư tư nhân và tăng trưởng kinh tế. 


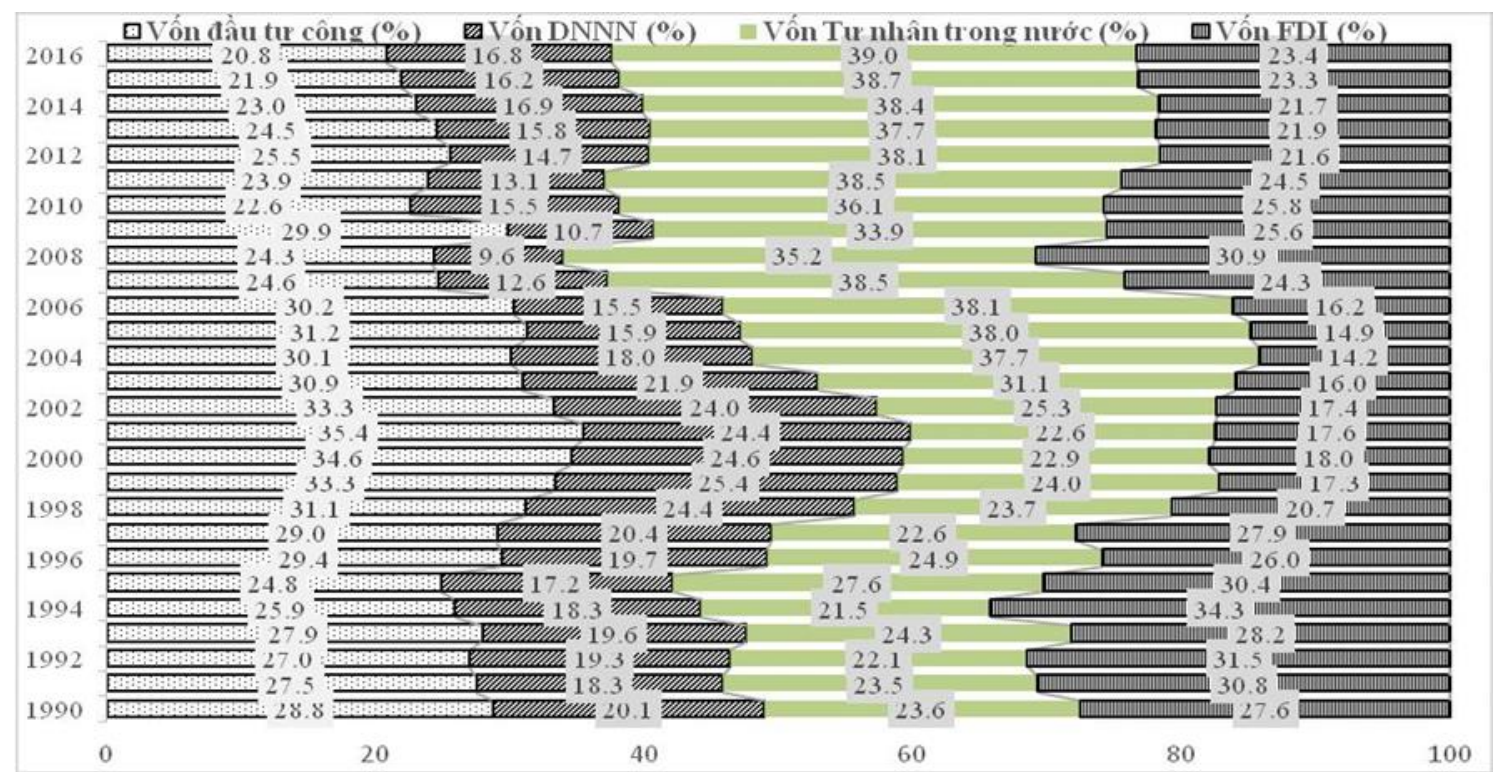

Hình 2. Cơ cấu vốn đầu tư theo hình thức sở hữu và vốn đầu tư công theo giá thực tế giai đoạn 1990-2016 (\%)

Nguồn: Tính toán của nhóm tác giả từ nguồn của Tổng cục Thống kê Việt Nam

Đầu tư công là đầu tư vào cơ sở hạ tầng được xem như là vốn mồi để thu hút đầu tư tư nhân trong và ngoài nước vào sản xuất kinh doanh. Giai đoạn đầu mới mở cửa đầu tư công thu hút đầu tư vào sản xuất kinh doanh và hệ số thu hút đầu tư khu vực tư nhân cao hơn. Theo đó, một đồng vốn đầu tư công thu hút từ 2,1-3,3 đồng vốn vào sản xuất kinh doanh và thu hút từ 1,4 - 2,7 đồng vốn từ khu vực tư nhân (Hình 3).

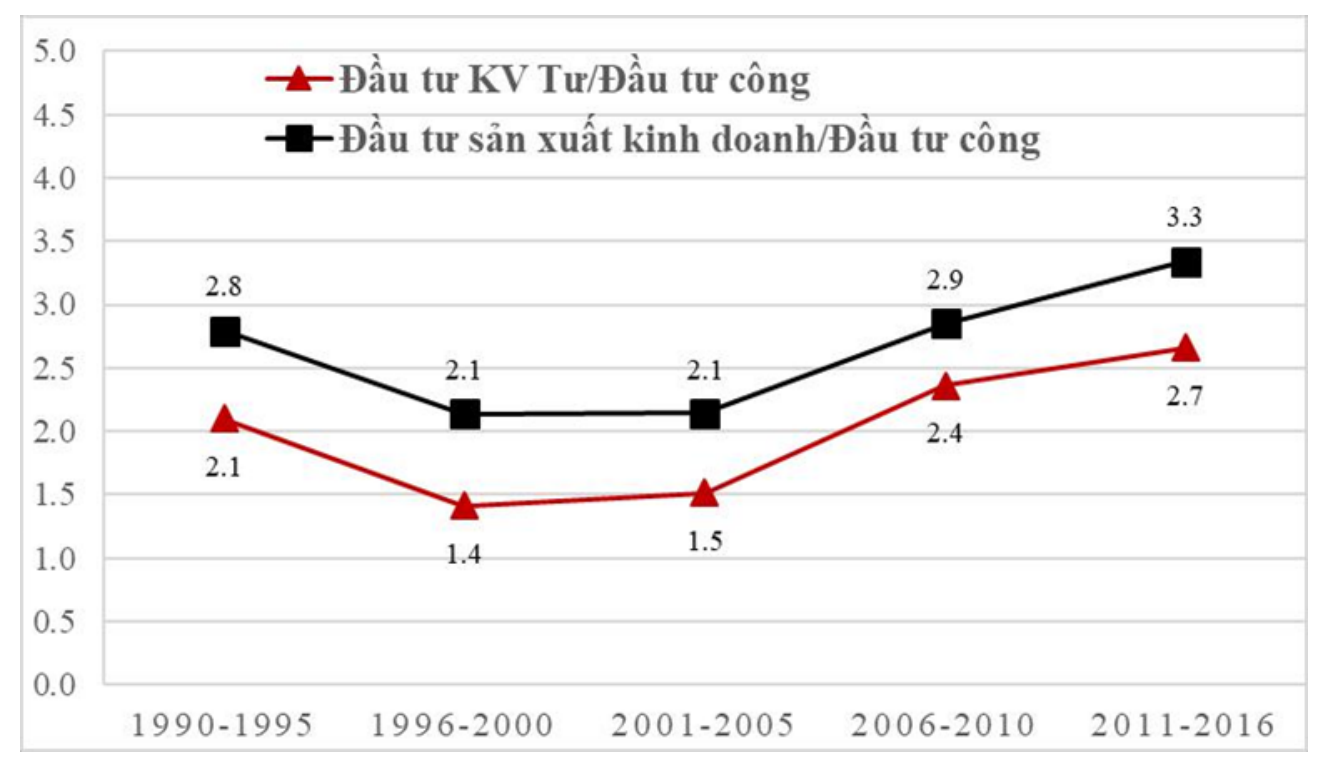

Hình 3. Hệ số thu hút đầu tư cho sản xuất kinh doanh và thu hút đầu tư tư nhân trên 1 đồng đầu tư công

Nguồn: Tính toán của tác giả từ số liệu Tổng cục Thống kê cung cấp 
Thực tế cho thấy tổng vốn đầu tư toàn xã hội theo GDP tăng đều qua các giai đoạn, từ 27,2\% GDP (1990-1995) lên 32,3\% GDP (2011-2016) một phần là do môi trường đầu tư, môi trường kinh doanh được cải thiện, trong đó có vai trò của đầu tư công cho cơ sở hạ tầng. Tốc độ tăng đầu tư công có biến động mạnh hơn tốc độ tăng trưởng GDP, một mặt do tác động của khủng hoảng kinh tế khu vực châu Á năm 1997 và khủng hoảng tài chính thế giới năm 2008, mặt khác do đầu tư công phụ thuộc vào tiến độ giải ngân của các dự án cũng như các nguồn vốn ngân sách nhà nước và vốn vay (Hình 4).

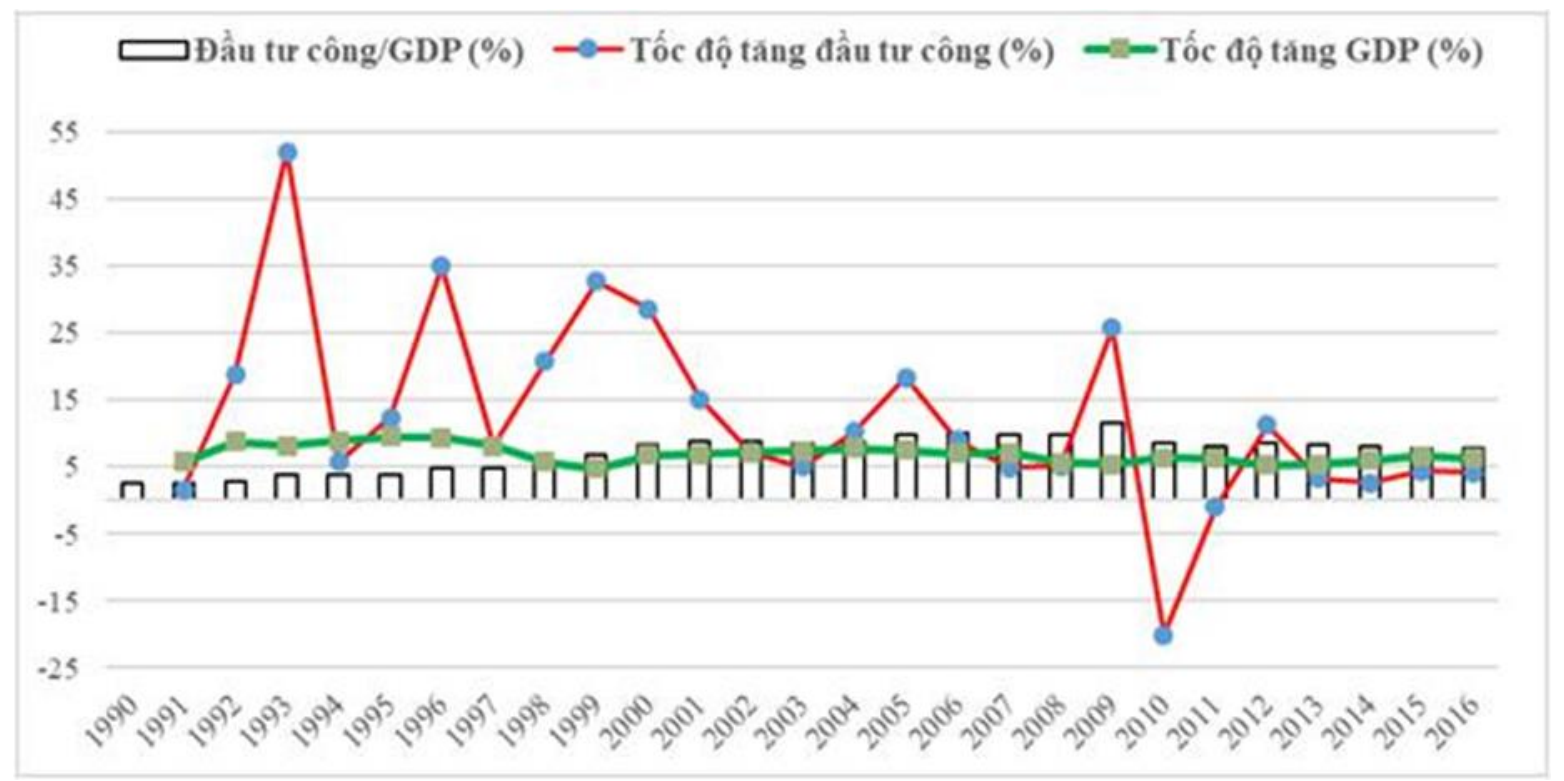

Hình 4. Tốc độ tăng đầu tư công và tăng trưởng kinh tế

Nguồn: Tính toán của tác giả từ số liệu Tổng cục Thống kê cung cấp

Từ phân tích ở trên cho thấy, nếu tách đầu tư công (đầu tư cho cơ sở hạ tầng) ra khỏi đầu tư cho khu vực DNNN (đầu tư cho sản xuất kinh doanh) sẽ thấy rõ vai trò của đầu tư công ít nhiều có tác động đến thu hút đầu tư tư nhân (tư nhân trong nước và $F D I$ ) và tăng trưởng kinh tế qua các biểu đồ mô tả mối quan hệ nêu trên. Dưới đây sẽ phân tích định lượng về tác động của đầu tư công đến thu hút đầu tư tư nhân và tăng trưởng kinh tế.

\section{Phương pháp và dữ liệu nghiên cứu}

Bài nghiên cứu này xem xét mối quan hệ lâu dài giữa các loại đầu tư bao gồm đầu tư của khu vực nhà nước, đặc biệt là đầu tư công, đầu tư tư nhân trong nước và đầu tư nước ngoài (FDI) với tăng trưởng kinh tế. Nghiên cứu cũng xem xét tác động đầu tư của khu vực nhà nước, đặc biệt là đầu tư công đối với đầu tư tư nhân để xác định xem đầu tư của khu vực nhà nước, đầu tư công có gây ảnh hưởng "hỗ trợ" hay "chèn lấn" đầu tư tư nhân. Để làm được điều này, nghiên cứu sử dụng các số liệu thống kê được cập nhật với sự hỗ trợ của các chuyên gia Tổng Cục Thống kê Việt Nam. Theo phân ngành của Tổng cục thống kê Việt Nam, toàn bộ nền kinh tế được phân thành 22 ngành cấp 1 (Nông nghiệp; Lâm nghiệp; Thủy sản; Khai khoáng; Công nghiệp chế biến, chế tạo; Sản xuất và phân phối điện, khí đốt, nước nóng, hơi nước và điều hòa không khí; Cung cấp nước; hoạt động quản lý và xử lý rác thải, nước thải; Xây dựng; Bán buôn và bán lẻ; sửa chữa ô tô, mô tô, xe máy và xe có động cơ khác; Vận tải kho bãi; Dịch vụ lưu trú 
và ăn uống; Thông tin và truyền thông; Hoạt động tài chính, ngân hàng và bảo hiểm; Hoạt động kinh doanh bất động sản; Hoạt động chuyên môn, khoa học và công nghệ; Hoạt động hành chính và dịch vụ hỗ trợ; Hoạt động của Đảng Cộng sản, tổ chức chính trị-xã hội; Quản lý Nhà nước, an ninh quốc phòng; Đảm bảo xã hội bắt buộc; Giáo dục và đào tạo; Y tế và hoạt động trợ giúp xã hội; Nghệ thuật, vui chơi và giải trí; Hoạt động dịch vụ khác; Hoạt động làm thuê các công việc trong các hộ gia đình, sản xuất sản phẩm vật chất và dịch vụ tự tiêu dùng của hộ gia đình). Nhờ có sự hỗ trợ của các chuyên gia Vụ quản lý vốn, Tổng cục Thống kê, số liệu vốn đầu tư công được tách ra từ số liệu vốn đầu tư của khu vực nhà nước phân theo ngành cấp 1. Tổng cộng bộ dữ liệu bảng trong nghiên cứu này cũng bao gồm 594 mẫu quan sát.

Điểm khác biệt của nghiên cứu này so với các nghiên cứu trước là các nghiên cứu trước phân tích số liệu chuỗi của một quốc gia hoặc số liệu bảng của một nhóm quốc gia, trong khi nghiên cứu của chúng tôi là phân tích số liệu bảng theo ngành, nhóm ngành kinh tế. Như đã đề cập, đầu tư công là hoạt động đầu tư của nhà nước vào các chương trình, dự án xây dựng kết cấu hạ tầng kinh tế - xã hội và đầu tư vào các chương trình, dự án phục vụ phát triển kinh tế xã hội. Vì vậy, hầu hết các ngành kinh tế ở Việt Nam đều có đầu tư công cho kết cấu hạ tầng của ngành cũng như phục vụ phát triển kinh tế chung. Tuy nhiên, theo số liệu công bố của Tổng cục Thống kê Việt Nam, số liệu vốn đầu tư được phân theo ba khu vực: Nhà nước, Tư nhân trong nước và Đầu tư nước ngoài. Đầu tư của khu vực nhà nước bao gồm cả đầu tư công cho xây dựng kết cấu hạ tầng kinh tế - xã hội và đầu tư của doanh nghiệp nhà nước cho sản xuất kinh doanh. Vì vậy để phân tích tác động của đầu tư công chúng tôi tách tổng đầu tư xã hội ra thành 4 loại: Đầu tư công; Đầu tư của doanh nghiệp nhà nước cho sản xuất kinh doanh; Đầu tư của doanh nghiệp tư nhân trong nước; và Đầu tư của các doanh nghiệp có vốn đầu tư nước ngoài. Vốn đầu tư của mỗi loại được tính bình quân cho một năm. Do số liệu vốn FDI tính bằng đồng đô la Mỹ, chúng tôi chuyển số liệu từ nguồn của Tổng cục Thống kê Việt Nam tính theo đồng nội tệ (Việt Nam đồng) sang số liệu tính theo đô la Mỹ. Khi đưa vào mô hình nghiên cứu đánh giá tác động của đầu tư công đối với đầu tư tư nhân và tăng trưởng kinh tế, chúng tôi đưa 4 biến gồm GDP, Tổng đầu tư khu vực tư nhân (đầu tư tư nhân trong nước + đầu tư FDI), Đầu tư công và Tổng đầu tư của khu vực nhà nước (đầu tư công + đầu tư của doanh nghiệp nhà nước). Các biến được sử dụng trong nghiên cứu này được mô tả qua Bảng 1 .

\section{Bảng 1}

Mô tả các biến sử dụng trong mô hình

\begin{tabular}{|l|c|l|c|}
\hline \multicolumn{1}{|c|}{ Tên biến } & Ký hiệu & \multicolumn{1}{|c|}{ Nguồn dữ liệu } & Đơn vị \\
\hline Đầu tư công ngành $\mathrm{i}$ vào năm $\mathrm{t}$ & GI $_{\mathrm{it}}$ & $\begin{array}{l}\text { GSO, quy đồi theo tỷ giá bình } \\
\text { quân hàng năm }\end{array}$ & Tỷ USD \\
\hline $\begin{array}{l}\text { Thu nhập quốc nội GDP theo ngành } \\
\text { i vào năm } \mathrm{t}\end{array}$ & $\mathrm{Y}_{\mathrm{it}}$ & $\begin{array}{l}\text { GSO, quy đồi theo tỷ giá bình } \\
\text { quân hàng năm }\end{array}$ & Tỷ USD \\
\hline $\begin{array}{l}\text { Tồng đầu tư nhà nước cho ngành } \mathrm{i} \\
\text { vào năm } \mathrm{t}\end{array}$ & GEIGI $_{\mathrm{it}}$ & $\begin{array}{l}\text { Tổng đầu tư công và đầu tư của } \\
\text { DNNN }(\mathrm{GI}+\mathrm{GEI})\end{array}$ & Tỷ USD \\
\hline $\begin{array}{l}\text { Tổng đầu tư khu vực tư nhân cho } \\
\text { ngành } \mathrm{i} \text { vào năm } \mathrm{t}\end{array}$ & PEIFDI $_{\mathrm{it}}$ & $\begin{array}{l}\text { Tồng đầu tư tư nhân trong nước } \\
\text { và đầu tư FDI (PEI + FDI) }\end{array}$ & Tỷ USD \\
\hline
\end{tabular}

Nguồn: Kết quả phân tích dữ liệu của nhóm nghiên cứu 
Nghiên cứu áp dụng các kiểm định nghiệm đơn vị và kiểm định đồng liên kết thể hiện mối quan hệ lâu dài giữa các biến xem xét.

Kiểm định nghiệm đơn vị (Unit Root Tests). Có một số cách tiếp cận để kiểm định nghiệm đơn vị được áp dụng bao gồm Breitung (2002), Levin, Lin, và Chu (2002), Im, Pesaran, và Shin (2003); Augmented Dickey-Fuller ( $\mathrm{ADF}$ ) và Phillips-Perron $(\mathrm{PP})$. Các kiểm định này thường được trích dẫn trong các nghiên cứu thực nghiệm và dựa trên các giả định khác nhau. Breitung (2002) và Levin và cộng sự (2002) đề xuất một kiểm định với giả thuyết không hợp lệ của nghiệm đơn vị tự hồi quy đồng nhất, trong khi đó Im và cộng sự (2003) kiểm định giả thuyết không đổi của nghiệm đơn vị tự hồi quy không đồng nhất. Nói cách khác, Levin và cộng sự (2002) kiểm định cho một quá trình chung nghiệm đơn vị, còn Im và cộng sự (2003) kiểm định cho một quá trình riêng nghiệm đơn vị.

Nghiên cứu của chúng tôi sử dụng cả bốn loại kiểm định nghiệm đơn vị, cụ thể là sử dụng kiểm định của Levin và cộng sự (2002), Im và cộng sự (2003) và Augmented DickeyFuller (ADF) và Phillips-Perron (PP) đối với bản chất của nghiệm đơn được thiết lập của chuỗi một cách thận trọng. Hơn nữa, các kiểm định nghiệm đơn vị bảng được chứng minh là tốt hơn so với các kiểm định nghiệm đơn vị theo chuỗi thời gian cá biệt thông thường.

Kiểm định đồng liên kết (Co-integration test). Để tìm ra tác động dài hạn, cần phải kiểm định và thiết lập mối quan hệ đồng liên kết giữa các biến không dừng bằng cách sử dụng các phương pháp liên quan đến kiểm định đồng liên kết. Để đảm bảo tính tin cậy về bản chất đồng liên kết của sự kết hợp các biến, chúng tôi sử dụng đề xuất của Pedroni $(1999,2001)$ và kiểm định đồng liên kết của Fisher (Johansen, 1988). Nếu trị số thống kê kiểm định bác bỏ giả thuyết Ho của nghiệm đơn vị cho một sự kết hợp các biến cụ thể, một mối quan hệ lâu dài giữa các biến này sẽ được thiết lập. Pedroni phát triển bảy loại thống kê dựa trên số dư ước tính, trong đó có bốn loại là thống kê bảng và thu được bằng cách tính trung bình số dư trong bảng, và ba loại khác đạt được bằng cách tính trung bình số dư cắt chéo theo bảng hoặc thống kê trung bình nhóm. Theo cách thực hiện của Pedroni $(1999,2001)$, bảng ngắn có thể là một trở ngại vì chúng có thể làm suy yếu sức mạnh của kiểm định. Trên thực tế, Bénassy-Quéré, Fontagne, và Lahreche-Revil (2005) đề xuất rằng trong các bảng ngắn, bảng tham số và thống kê $\mathrm{ADF}$ nhóm cung cấp kết quả đáng tin cậy nhất, trong khi kiểm định thống kê rho-statistic theo nhóm là cách thực hiện kém nhất. Do đó, chúng tôi căn cứ vào trật tự này để quyết định bản chất đồng liên kết của các biến trong nghiên cứu.

Nếu theo các kiểm định này tìm thấy có mối quan hệ đồng liên kết giữa các biến không dừng ở cấp bậc nào đó của biến, khi đó sẽ tiến hành ước tính mối quan hệ dài hạn bằng các phương pháp thích hợp. Đối với việc tính toán phương trình đồng liên kết (hoặc mối quan hệ dài hạn), mặc dù phương pháp OLS là nhất quán ngay cả đối với dữ liệu bảng, các sai số chuẩn được tạo ra không có giá trị đối với các kết luận thống kê do sai lệch tiệm cận bậc hai (Lee, 2007). Do đó, để có được số liệu thống kê hợp lệ cho suy luận, một số phương pháp sẽ được áp dụng, chẳng hạn như phương pháp điều chỉnh OLS đầy đủ (Fully Modified OLS - viết tắt FMOLS) và phương pháp OLS động (Dynamic OLS - viết tắt DOLS). 


\section{Kết quả nghiên cứu}

Bảng 2 thể hiện các kết quả về kiểm định nghiệm đơn vị bảng theo Im và cộng sự (2003); Augmented Dickey-Fuller (ADF) và Phillips-Perron (PP). Các kết quả cho thấy sự phù hợp là tất cả các chuỗi không dừng ở cấp độ của các biến, cụ thể là các biến $\mathrm{y}$, gi, peifdi và geigi. Tuy nhiên, các kiểm định tương tự đã bác bỏ giả thuyết (Ho) của thực hiện nghiệm đơn tại mức ý nghĩa $1 \%$ đối với các biến trên khi chúng được biến đổi thành sai phân bậc 1 . Do đó, có thể kết luận rằng các biến $\mathrm{y}$, gi, geigi và peifdi là các biến dừng ở bậc 1 hay $\mathrm{I}(1)$.

\section{Bảng 2}

Kết quả kiểm định nghiệm đơn vị (Unit Root Tests)

\begin{tabular}{|l|c|c|c|c|}
\hline \multicolumn{1}{|c|}{ Phương pháp kiểm định } & IPS & PP & LLC & Fisher \\
\hline Các biến theo mức độ & & & & \\
\hline y & 13.3050 & 0.04433 & 8.78963 & 0.24034 \\
\hline gi & 3.60612 & 10.1860 & 0.11405 & 8.99033 \\
\hline geigi & 7.30046 & 12.518 & 4.1196 & 12.518 \\
\hline peifdi & 11.1223 & 5.98434 & 9.90568 & 5.98434 \\
\hline Các biến theo sai phân bậc 1 & & & & \\
\hline y & $-5.08509 * * *$ & $198.359 * * *$ & $-5.74113 * * *$ & $96.3919 * * *$ \\
\hline gi & $-13.9087 * * *$ & $352.412 * * *$ & $-12.0212 * * *$ & $217.689 * * *$ \\
\hline geigi & $-24.3882 * * *$ & $515.234 * * *$ & $-24.4911 * * *$ & $515.234 * * *$ \\
\hline peifdi & $-13.2405 * * *$ & $350.857 * * *$ & $-14.5832 * * *$ & $350.857 * * *$ \\
\hline
\end{tabular}

Ghi chú: *,**,*** có ý nghĩa thống kê ở mức $10 \%, 5 \%$ và $1 \%$. Độ trễ được chọn dựa vào các tiêu chuẩn AIC. Các kiểm định IPS, (Im, Pesaran, Smith); LLC (Levin, Lin, Chu); PP (Phillips Perron) và Kiểm định Fisher theo Fisher - Johansen. Ho (Null hypothesis) trong mỗi kiểm định là có nghiệm đơn vị.

Nguồn: Kết quả xử lý từ dữ liệu điều tra

Khi các biến được tích hợp bậc 1, chúng tôi tiến hành kiểm định theo Pedroni (1999, 2001) để cho kiểm định đồng liên kết bảng, tại đó có thể tiến hành kiểm định cho một số kết hợp của các biến. Trong số bảy trị số thống kê kiểm định, chúng tôi chủ yếu dựa vào thống kê bảng và nhóm $\mathrm{ADF}$ để đưa đến kết luận về sự đồng liên kết của các biến. Chúng tôi sử dụng các kiểm định đồng liên kết Fisher để củng cố thêm quyết định cũng như xem liệu có tồn tại bất kỳ đồng liên kết nào giữa các biến hay không. Dựa vào mục tiêu nghiên cứu, chúng tôi thực hiện các kiểm định đồng liên kết về các mô hình dưới đây, với mô hình 1-2 phân tích mối quan hệ dài hạn giữa các loại hình đầu tư; với mô hình 3 và 4 thể hiện mối quan hệ dài hạn giữa các loại hình đầu tư và GDP ngành:

$$
\begin{aligned}
& \text { peifdi } i_{i t}=\beta_{0}+\beta_{1} g i_{i t}+\varepsilon_{i t} \\
& \text { peifdi } i_{i t}=\beta_{0}+\beta_{1} g e i g i_{i t}+\varepsilon_{i t} \\
& y_{i t}=\beta_{0}+\beta_{1} \text { peifdi } i_{i t}+\beta_{2} \text { geigi } i_{i t}+\varepsilon_{i t} \\
& y_{i t}=\beta_{0}+\beta_{1} g i_{i t}+\varepsilon_{i t}
\end{aligned}
$$


Các kết quả của các kiểm định đồng liên kết cho các mô hình 1-4 được trình bày trong các Bảng 3 và Bảng 4 . Theo Bảng 3 và Bảng 4 , gần như tất cả các trị số thống kê theo kiểm định của Pedroni $(1999,2001)$ đều cung cấp bằng chứng mạnh mẽ về sự tồn tại đồng liên kết giữa các biến y, peifdi, geigi và gi. Đặc biệt, các trị số thống kê $\mathrm{ADF}$ - Bảng và $\mathrm{ADF}-\mathrm{Nhóm}$ có ý nghĩa ở mức $1 \%$ cho tất cả các mô hình, và chỉ có duy nhất trị số thống kê rho theo nhóm cho mô hình 3 có ý nghĩa thống kê ở mức $10 \%$. Bên cạnh thử nghiệm đồng liên kết theo phương pháp Pedroni, chúng tôi sử dụng kiểm định Fisher để xác định chắc chắn bản chất của mối liên hệ giữa các biến. Các kết quả một lần nữa cho thấy rằng các trị số thống kê kiểm định của Fisher cho tất cả các mô hình đã bác bỏ giả thuyết không đồng liên kết của các biến một cách mạnh mẽ. Từ các kết quả này, có thể đi đến kết luận rằng có sự tồn tại mối quan hệ đồng liên kết trong tất cả các mô hình. Nói cách khác, đây là những mối quan hệ dài hạn sẽ được ước lượng trong bước tiếp theo.

\section{Bảng 3}

Kiểm định đồng liên kết cho các mô hình 1-4 theo Pedroni

\begin{tabular}{|c|c|c|c|c|c|c|c|}
\hline Model & Panel v & Panel rho & Panel PP & Panel ADF & Group rho & Group PP & Group ADF \\
\hline \multirow{2}{*}{1} & $4.559794 * * *$ & $3.660681 * * *$ & $2.775124 * * *$ & $2.947321 * * *$ & $4.729435 * * *$ & $5.749737 * * *$ & $-6.02814 * * *$ \\
\hline 2 & $11.38107 * * *$ & $9.208029 * * *$ & $-6.42381 * * *$ & $5.817672 * * *$ & $5.434107 * * *$ & $-7.18715 * * *$ & $4.906681 * * *$ \\
\hline \multirow{2}{*}{3} & $4.468027 * * *$ & $3.511605 * * *$ & $3.724917 * * *$ & $-2.074787 * *$ & $-1.425112 *$ & $3.175936 * * *$ & $5.102904 * * *$ \\
\hline & & - & - & - & - & - & - \\
\multirow{2}{*}{4} & $7.532648 * * *$ & $11.31355^{* * *}$ & $8.108176 * * *$ & $8.677381 * * *$ & $2.925939 * * *$ & $3.675493 * * *$ & $-5.09253 * * *$ \\
\hline
\end{tabular}

*, **, ***. có ý nghĩa thống kê ở mức $10 \%, 5 \%$ và $1 \%$. Độ trễ được chọn dựa vào các tiêu chuẩn AIC.

Nguồn: Kết quả phân tích dữ liệu của nhóm nghiên cứu

\section{Bảng 4}

Tóm lược kiểm định đồng liên kết cho các mô hình 1-4 theo Fisher

\begin{tabular}{|c|c|c|}
\hline Model & Variable & Ho: Không có quan hệ đồng tích hợp \\
\hline 1 & peifdi gi & bác bỏ \\
\hline 2 & peifdi geigi & bác bỏ \\
\hline 3 & y peifdi geigi & bác bỏ \\
\hline 4 & y gi & bác bỏ \\
\hline
\end{tabular}

Ghi chú: Các trị số kiểm định thống kê có ý nghĩa ở mức 5\%.

Nguồn: Kết quả phân tích dữ liệu của nhóm nghiên cứu

Sau khi thiết lập quan hệ đồng liên kết giữa các biến, chúng tôi tiến hành ước lượng mối quan hệ dài hạn dựa trên 4 mô hình để tìm hiểu đầu tư công và đầu tư của khu vực nhà nước (bao gồm đầu tư công và đầu tư từ các doanh nghiệp nhà nước (DNNN)) ảnh hưởng đến tổng đầu tư tư nhân (bao gồm đầu tư tư nhân trong nước và đầu tư trực tiếp nước ngoài (peifdi)) trong dài hạn. Sau đó, sẽ phân tích mối quan hệ giữa các loại hình đầu tư này với tăng trưởng kinh tế, xem đâu là động lực quan trọng cho sự tăng trưởng kinh tế. 
Bảng 5 trình bày các kết quả ước lượng về mối quan hệ giữa các loại hình đầu tư. Trong mô hình 1 , kết quả ước lượng theo DOLS - Nhóm cho thấy đầu tư công (gi) có ảnh hưởng tích cực đến tổng đầu tư tư nhân (gồm đầu tư tư nhân trong nước và FDI). Trong mô hình 2 , cả đầu tư công và đầu tư từ các doanh nghiệp nhà nước được gộp lại để đại diện cho tổng đầu tư từ khu vực nhà nước. Kết quả của mô hình 2 khẳng định vai trò của đầu tư khu vực nhà nước trong việc thúc đẩy tổng đầu tư tư nhân, cũng như các thành phần của nó (đầu tư tư nhân trong nước và đầu tư trực tiếp nước ngoài). Kết quả từ ước lượng theo DOLS và FMOLS luôn thống nhất với nhau, cho thấy kết quả ước lượng có độ tin cậy cao. Ngoài ra, có một chi tiết đáng chú ý là xét hệ số trong 2 cột DOLS và FMOLS grouped, khi hai loại đầu tư công và đầu tư của DNNN gộp lại (biến geigi) thì tác động có vẻ ít tích cực hơn so với khi chỉ có tác động của đầu tư công (gi). Điều này cung cấp một số bằng chứng cho thấy đầu tư của DNNN có thể không hiệu quả bằng đầu tư công trong việc thu hút hay khuyến khích đầu tư tư nhân (tức chèn lấn đầu tư tư nhân).

\section{Bảng 5}

Kết quả ước lượng theo DOLS và FMOLS của các mô hình 1-2

\begin{tabular}{|c|l|l|l|l|r|c|}
\hline \multirow{2}{*}{ Mô hình } & \multicolumn{2}{|c|}{ Biến } & \multicolumn{2}{|c|}{ DOLS } & \multicolumn{2}{c|}{ FMOLS } \\
\cline { 2 - 4 } & Dep var & \multicolumn{2}{|c|}{ Regressors } & Pooled & Grouped & \multicolumn{2}{c|}{ Pooled } & Grouped \\
\hline 1 & peifdi & gi & $0.942737 * * *$ & $11.23833 * * *$ & $0.897564 * * *$ & $11.03689 * * *$ \\
\hline 2 & peifdi & geigi & $1.144212 * * *$ & $6.950187 * * *$ & $1.34981 * * *$ & $6.797065 * * *$ \\
\hline
\end{tabular}

Ghi chú: *,**,*** thể hiện mức ý nghĩa thống kê tương ứng $10 \%, 5 \%$ và $1 \%$

Nguồn: Kết quả xử lý từ dữ liệu điều tra

Bảng 6 trình bày kết quả các ước lượng cho mối quan hệ dài hạn giữa các loại hình đầu tư và tăng trưởng GDP. Trong mô hình 3 , biến tổng đầu tư tư nhân (PEIFDI) (tổng đầu tư tư nhân bao gồm đầu tư tư nhân trong nước và đầu tư nước ngoài) và biến tổng đầu tư nhà nước (GEIGI) (tổng đầu tư của khu vực nhà nước bao gồm đầu tư công và đầu tư của các doanh nghiệp nhà nước) được coi là động lực chính của tăng trưởng kinh tế. Kết quả ước lượng cho thấy đầu tư khu vực nhà nước tác động đến tăng trưởng kinh tế không mạnh bằng đầu tư của khu vực tư nhân trong thúc đẩy tăng trưởng kinh tế.

Trong mô hình 4 , chúng tôi cho thấy gi (đầu tư công) có tác động tích cực đến GDP ngành, một lần nữa nhấn mạnh tầm quan trọng của đầu tư công trong cung cấp cơ sở hạ tầng cho đầu tư tư nhân và thúc đẩy tăng trưởng kinh tế. Cũng như kết quả của mô hình 3 và 4 , có bằng chứng cho thấy đầu tư của DNNN kém hơn đầu tư công, khi đầu tư DNNN gộp vào đầu tư công thì hệ số tác động thấp (3,371367 đối với DOLS grouped), nhưng khi chỉ có riêng đầu tư công thì hệ số tác động rất cao (trên 31 ).

Tóm lại, kết quả trên đã cho bằng chứng nhất quán về hiệu quả tích cực của đầu tư từ cả khu vực tư nhân và khu vực nhà nước đối với GDP ngành ở Việt Nam. Rõ ràng chi tiêu của khu vực nhà nước không chỉ giúp thúc đẩy đầu tư của khu vực tư nhân mà còn thúc đẩy GDP trong dài hạn. Bằng chứng này rất quan trọng trong việc quyết định có nên duy trì đầu tư từ khu vực nhà nước hay không. Tuy nhiên, khoản đầu tư từ các doanh nghiệp nhà nước (DNNN) có xu hướng thể hiện nhược điểm rõ ràng, vì khi kết hợp đầu tư của DNNN với đầu tư công cho thấy ảnh hưởng của đầu tư nhà nước có tác động làm giảm tác động tích cực đối với GDP. 


\section{Bảng 6}

Kết quả ước lượng các mô hình 3 - 4 theo DOLS và FMOLS

\begin{tabular}{|c|c|c|c|c|c|c|}
\hline \multirow[b]{2}{*}{ Mô hình } & \multicolumn{2}{|c|}{ Biến } & \multicolumn{2}{|l|}{ DOLS } & \multicolumn{2}{|l|}{ FMOLS } \\
\hline & $\begin{array}{c}\text { Biến phụ } \\
\text { thuộc }\end{array}$ & Biến giải thích & Pooled & Grouped & Pooled & Grouped \\
\hline 3 & $\mathrm{y}$ & PEIFDI & $2.535821 * * *$ & $3.638536^{* * * *}$ & $2.43086^{* * *}$ & $2.414649 * * *$ \\
\hline & & GEIGI & 1.331646 *** & $3.371367 * * *$ & $2.233894 * * *$ & $3.712089 * * *$ \\
\hline 4 & $\mathrm{y}$ & GI & $4.429998 * * *$ & $31.48279 * * *$ & $4.74006^{* * *}$ & $32.77765^{* * *}$ \\
\hline
\end{tabular}

Ghi chú: *,**,*** thể hiện mức ý nghĩa thống kê tương ứng $10 \%, 5 \%$ và $1 \%$

Nguồn: Kết quả xử lý từ dữ liệu điều tra

\section{Kết luận và hàm ý chính sách cho đầu tư công và đầu tư của khu vực nhà nước nói chung tại Việt Nam}

Chính phủ Việt Nam không chỉ tham gia cung cấp hàng hóa, dịch vụ công và đầu tư cơ sở hạ tầng để tạo môi trường kinh doanh thuận lợi nhằm thu hút đầu tư tư nhân và đầu tư nước ngoài FDI, mà còn trực tiếp tham gia vào hoạt động sản xuất kinh doanh thông qua các doanh nghiệp nhà nước. Qua lịch sử phát triển, Việt Nam đã chuyển từ nền kinh tế kế hoạch tập trung sang nền kinh tế thị trường. Trong quá trình này mặc dù khu vực tư nhân đã phát triển qua nhiều năm, khu vực nhà nước vẫn còn chiếm ưu thế.

Nghiên cứu áp dụng phương pháp đồng liên kết (Fully Modified OLS và Dynamic Panel OLS) để đánh giá tác động dài hạn của đầu tư công lên đầu tư tư nhân và tăng trưởng kinh tế bằng cách sử dụng dữ liệu từ 22 ngành kinh tế cấp 1 trong khoảng thời gian 27 năm (19902016). Nghiên cứu đã có được bằng chứng nhất quán về hiệu quả tích cực của đầu tư công và đầu tư tư nhân đối với tăng GDP ngành ở Việt Nam. Kết quả cho thấy, đầu tư công không chỉ giúp thúc đẩy đầu tư của khu vực tư nhân mà còn làm tăng GDP trong thời gian dài hạn. Bằng chứng này rất quan trọng trong việc quyết định có nên duy trì đầu tư từ khu vực chính phủ hay không. Tuy nhiên, có một số bằng chứng cho thấy đầu tư từ doanh nghiệp nhà nước không hiệu quả, vì khi kết hợp đầu tư của DNNN với đầu tư công cho thấy ảnh hưởng của tổng đầu tư nhà nước có tác động làm giảm GDP. Kết quả này gợi ý cần cơ cấu lại các doanh nghiệp nhà nước ở Việt Nam. Nghiên cứu cũng chỉ ra rằng tổng đầu tư tư nhân gồm đầu tư tư nhân trong nước và đầu tư nước ngoài FDI đều đóng một vai trò quan trọng trong việc kích thích tăng trưởng kinh tế. Nhìn chung, kết quả của chúng tôi tương đối phù hợp với các nghiên cứu trước đó, như nghiên cứu của Barro (1990) hay nghiên cứu ở Phetsavong và Ichihashi (2012) ở các nước đang phát triển châu Á, nơi mà đầu tư công (đầu tư vào cơ sở hạ tầng) thu hút đầu tư tư nhân và thúc đẩy tăng trưởng kinh tế.

Từ các kết quả nêu trên, dưới đây sẽ đưa ra một số gợi ý và một số khuyến nghị chính sách cụ thể hơn bao gồm:

Thứ nhất, rõ ràng là đầu tư công là "vốn mồi" cho đầu tư của khu vực tư nhân - là khu vực động lực tăng trưởng kinh tế. Để làm cho đầu tư công trở nên ổn định và trở thành nhân tố “thúc đẩy”, chính phủ cần có một kế hoạch đầu tư dài hạn mang tính chiến lược để giảm thiểu sự không chắc chắn của đầu tư công (nghĩa là điều chỉnh tăng/giảm sự bất ổn); 
Thứ hai, đầu tư tư nhân trong nước có vai trò rất lớn trong việc kích thích tăng trưởng kinh tế, ngoài đầu tư từ nguồn vốn FDI. Do đó, chính sách của Việt Nam cần tạo động lực cho khu vực tư nhân trong nước phát triển chứ không chỉ ưu tiên cho các doanh nghiệp FDI;

Thứ ba, vì đầu tư của khu vực nhà nước bao gồm đầu tư vào cơ sở hạ tầng và đầu tư của các doanh nghiệp nhà nước vào hoạt động sản xuất kinh doanh, nhưng vai trò của các doanh nghiệp nhà nước cần được xem xét kỹ lưỡng để đảm bảo tác động hiệu quả hơn tới tăng trưởng kinh tế. Kết quả nghiên cứu chỉ ra rằng do có sự kém hiệu quả của các doanh nghiệp nhà nước, vì vậy nghiên cứu đề xuất cần giảm bớt sự can thiệp của chính phủ vào lĩnh vực sản xuất kinh doanh bằng cách tiếp tục cổ phần hóa DNNN nhằm thu hẹp khu vực này trong nền kinh tế, thoái vốn từ khu vực DNNN cổ phần hóa để tăng cường đầu tư công cho cơ sở hạ tầng nhằm thu hút đầu tư tư nhân và tăng trưởng kinh tế.

\section{LÒ̀I CẢM ƠN}

Nghiên cứu này được tài trợ bởi ngân sách của ĐHQG-HCM với mã số đề tài No B201634-01.

\section{Tài liệu tham khảo}

Auschauer, D. A. (1989). Is public expenditure productive? Journal of Monetary Economics, 23(2), 177-200. doi:10.1016/0304-3932(89)90047-0

Barro, R. (1990). Government spending in a simple model of economic growth. Journal of Political Economy, 98(5), S103-S125.

Bénassy-Quéré, A., Fontagne, L., \& Lahreche-Revil, A. (2005). How does FDI react to corporate taxation? International Tax and Public Finance, 12(5), 583-603. https://link.springer.com/article/10.1007/s10797-005-2652-4

Breitung, J. (2002). The local power of some unit root tests for panel data. Advances in Econometrics, 15, 161-178.

Bukhari, S. A., Ali, L., \& Saddaqat, M. (2007). Public investment and economic growth in the Three Little Dragons: Evidence from heterogeneous dynamic panel data international. Journal of Business and Information, 2(1), 57-79.

Dreger, C., \& Reimers, H. (2016). Does public investment stimulate private investment? Evidence for the euro area. Economic Modelling, 58, 154-158.

Gujarati, D. N., \& Porter, D. C. (2009). Basic econometrics (5th ed.). New York, NY: McGrawHill.

Haque, S. T. (2013). Effect of public and private investment on economic growth in Bangladesh: An econometric analysis. Research Study Series, 104-126.

Im, K. S., Pesaran, M. H., \& Shin, Y. (2003). Testing for unit roots in heterogeneous panels. Journal of Econometrics, 115, 53-74.

Johansen, S. (1988). Statistical analysis of cointegrating vectors. Econometric Reviews, 12, 231-254. 
Lee, G. (2007). Long run equilibrium relationship between inward FDI and productivity. Journal of Economic Development, 32(2), 183-192.

Levin, A., Lin, C. F., \& Chu, C. S. J. (2002). Unit root tests in panel data: Asymptotic and finite-sample properties. Journal of Econometrics, 108, 1-24.

Pedroni, P. (1999). Critical values for cointegration tests in heterogeneous panels with multiple regressors. Oxford Bulletin of Economics and Statistics, 61, 653-670.

Pedroni, P. (2001). Purchasing power parity tests in cointegrated panels. Review of Economics and Statistics, 83, 727-731.

Phetsavong, K., \& Ichihashi, M. (2012). The impact of public and private investment on economic growth: Evidence from developing Asian countries. Retrieved October 12, 2017, from https://home.hiroshima-u.ac.jp/ ichi/Kongphet2012.pdf

Reungsri, T. (2010). The impact of public infrastructure investment on economic growth in Thailand. (Doctoral dissertation), School of Economics and Finance, Victoria University, Australia.

Solow, R. (1956). A contribution to the theory of economic growth. The Quarterly Journal of Economics, 70(1), 65-94.

To, T. T. (2011). Đầu tư công "lấn át" đầu tư tư nhân? Góc nhìn từ mô hình thực nghiệm VECM [Public investment "overwhelms" private investment? Perspective from the experimental model VECM]. Tạp chí Tài chính, 6(560), 1-17.

Tran, T. N. N. A., \& Le, P. H. (2014). Tác động của đầu tư công đối với tăng trưởng kinh tế ở Việt Nam: Góc nhìn thực nghiệm từ mô hình ARDL [The impact of public investment on economic growth in Vietnam: An experimental perspective from the ARDL model]. Tap chí Phát triển và Hội nhập, 19, 3-10.

Vedder, R. K., \& Gallaway, L. E. (1998). Government size and economic growth- G-01 Dirksen building, Washington, DC 20510. Retrieved October 13, 2017, from http://www.house.gov/jec/

Zainah, P. (2009). The role of public investment in promoting economic growth: A case study of Mauritius. Retrieved October 13, 2017, from https://www.tips.org.za/researcharchive/trade-and-industry/southern-african-development-research-networksadrn/item/1926-the-role-of-public-investment-in-promoting-economic-growth-a-casestudy-of-mauritius 